\title{
Early alterations in vascular contractility associated to changes in fatty acid composition and oxidative stress markers in perivascular adipose tissue
}

Alejandro Rebolledo ${ }^{1 *}$, Oscar R Rebolledo², Carlos A Marra, María E García², Ana R Roldán Palomo', Laura Rimorini', Juan J Gagliardino

\begin{abstract}
Aim: To test the early effect of fructose-induced changes in fatty acid composition and oxidative stress markers in perivascular adipose tissue (PVAT) upon vascular contractility.

Methods: Adult male Wistar rats were fed a commercial diet without (CD) or with 10\% fructose (FRD) in the drinking water for 3 weeks. We measured plasma metabolic parameters, lipid composition and oxidative stress markers in aortic PVAT. Vascular contractility was measured in aortic rings sequentially, stimulated with serotonin (5-HT) and high $\mathrm{K}^{+}$-induced depolarization using intact and thereafter PVAT-deprived rings.
\end{abstract}

Results: Comparable body weights were recorded in both groups. FRD rats had increased plasma triglyceride and fructosamine levels. Their PVAT had an increased saturated to mono- or poly-unsaturated fatty acid ratio, a significant decrease in total superoxide dismutase and glutathione peroxidase activities and in the total content of glutathione. Conversely, lipid peroxidation (TBARS), nitric oxide content, and gluthathione reductase activity were significantly higher, indicating an increase in oxidative stress. In aortic rings, removal of PVAT increased serotonininduced contractions, but the effect was significantly lower in rings from FRD rats. This effect was no longer observed when the two contractions were performed in PVAT-deprived rings. PVAT did not affect the contractions triggered by high $\mathrm{K}^{+}$-induced depolarization either in CD or FRD rats.

Conclusions: FRD induces multiple metabolic and endocrine systemic alterations which also alter PVAT and the vascular relaxant properties of this tissue. The changes in PVAT would affect its paracrine modulation of vascular function.

\section{Background}

The metabolic syndrome (MS) is characterized by central adiposity, insulin resistance (IR), impaired glucose tolerance (IGT) or type 2 diabetes, hypertension and dyslipidemia. These factors predispose to greater risk for developing cardiovascular disease [1]. The increased consumption of unhealthy diets - particularly in Western societies - and a sedentary behavior have greatly contributed to the high prevalence of this

\footnotetext{
* Correspondence: ar@biol.unlp.edu.ar

'GINFIV - Grupo de Investigación en Fisiología Vascular, Grupo Vinculado a CENEXA (UNLP - CONICET LA PLATA), Facultad de Ciencias Exactas,

Universidad Nacional de La Plata, La Plata, Argentina

Full list of author information is available at the end of the article
}

condition [2]. In this context, fructose consumption has largely increased as a result of its addition to soft drinks and processed food [3].

Sucrose- or fructose-rich diets administered to normal rats induce metabolic alterations that resemble the profile of the human MS [4-8]; consequently, the fructoserich diet (FRD) constitutes a useful model for studying the role of unbalanced diets in the pathogenesis of the MS and cardiovascular disease. It has been shown that FRD promotes decreases in endothelial NO production [9] and vasorelaxation [10,11] as well as impaired insulininduced vasodilation [9]. Further, the FRD model is also useful to test the effects of different preventive strategies 
aimed at decreasing MS vascular morbidity and mortality.

We have recently shown that rats fed a FRD present marked changes in plasma lipid and hormone profile, oxidative damage to lipoprotein fractions and their fatty acids (FAs), fat content in the liver, and fatty acyl composition of total lipids in abdominal adipose tissue. These multiple abnormalities were associated with significant changes in insulin sensitivity and IGT, marked changes in liver glucose metabolism, decreased pancreatic $\beta$-cell mass, and increased production of reactive oxygen species (ROS) [12-16]. The latter effect, commonly described as oxidative stress, contributes to the development and progression of diabetes micro and macrovascular complications [17-19]. Supporting our data, it has been reported that FRD promotes oxidative damage, reducing antioxidant defenses and enhancing ROS production [3,12,20-22]. Time-sequential studies have detected enhanced ROS production as early as one week after FRD administration in aorta, heart and polymorphonuclear cells; besides, vascular and cardiac hypertrophy together with a rise in blood pressure have also been observed [23]. It is not known, however, whether these multiple and early FRD-induced disturbances also affect perivascular adipose tissue (PVAT).

The PVAT consists of a thin layer of fat located outside the adventitial layer, surrounding most systemic blood vessels. Originally, it was considered as a simple mechanical support for vasculature; however, recent studies have demonstrated that PVAT plays an active modulatory role on vessel function in a paracrine fashion through the release of either contractile or relaxant substances which act on the underlying vascular smooth muscle[24-29]. ROS are among the vasoactive products released by PVAT [30,31]. Additionally, recent studies performed in vivo have demonstrated a relationship between PVAT and insulin resistance: insulin sensitivity was negatively correlated with the amount of PVAT at the brachial artery [32].

In an attempt to provide an insight into the relationship of impaired PVAT metabolism/function and vascular reactivity, we fed normal rats with a FRD for 3 weeks to test: a) whether FRD reproduces the changes observed in abdominal adipose tissue (fatty acyl compositional changes and increased markers of oxidative stress) in PVAT, and b) the potential effect of these PVAT changes upon the vascular reactivity of aorta rings from control and FRD rats in response to different stimuli.

\section{Methods}

\section{Materials}

Thiobarbituric acid, CoA, N-ethylmaleimide, NAD+, $\operatorname{NADH}(\mathrm{H}), \mathrm{NADPH}(\mathrm{H})$, standards for oxidized and reduced glutathione, serotonin $(5-\mathrm{HT})$, organic and inorganic components for buffer preparations, teraetoxypropane and butylated hydroxytoluene were purchased from Sigma Chemical Co (St. Louis, Mo, USA). Sodium nitrite (99.8\% pure) was from Mallinckrodt (Griesheim, Germany). All solvents were HPLC-grade and provided by Carlo Erba (Milano, Italy). Lipid standards for c-gas liquid chromatography (c-GLC) identification were from Serdary Research Laboratories (London, Ontario, Canada). All standards were stored in appropriate solvents under nitrogen atmosphere at $-20^{\circ} \mathrm{C}$. Concentrations and purities were routinely checked by HPLC and/ or c-GLC. Other chemicals used were reagent grade and obtained from local commercial sources.

\section{Animals, plasma determinations and characteristics of the FRD-induced insulin resistance model}

Normal male Wistar rats weighing 180-200 g were maintained in a temperature-controlled environment $\left(23^{\circ} \mathrm{C}\right)$ with a fixed 12-hour light/dark cycle and fed a standard laboratory rat diet (Ganave, Argentina) for one week (stabilization period); the compositional analysis of this diet has been described elsewhere [33]. Rats were fed according to the American Institute of Nutrition [34]. After that period, rats were divided into two groups and fed the above mentioned diet and tap water (control diet, CD) during 3 weeks, or the same diet with the addition of $10 \%$ fructose into the drinking water (FRD). The fructose solution was freshly prepared and changed daily. In both groups, the relative FA content in the diet was 1.5\% 16:0, 2.1\% 18:0, 26.6\% $18: 1,57.3 \%$ 18:2 n-6, 1.4\% 18:3 n-3, 0.2\% 20:3 n-6, 0.2\% $20: 4 n-9,0.2 \% 20: 1$, and other FAs in trace amounts $(<0.2 \%)$ sufficient to cover the animals' nutritional requirements. Before sacrifice, blood samples were obtained from the retroorbital plexus under isoflurane (Florane, Abbot, Argentine) anesthesia; the samples were placed into chilled tubes with heparin, rapidly centrifuged at $4^{\circ} \mathrm{C}$ at $300 \times \mathrm{g}$, and immediately analyzed or stored at $-20^{\circ} \mathrm{C}$. Plasma triglycerides, glucose and fructosamine were measured using commercial kits (Bio Systems Diagnostics, Argentina) implemented in an automated clinical analyzer. Insulin levels were determined by radioimmunoassay using rat insulin standard. Insulin resistance was assessed with the HOMA score, calculated with the formula: fasting plasma insulin $(\mu \mathrm{U} / \mathrm{ml}) \times$ fasting plasma glucose $(\mathrm{mmol} / \mathrm{l}) / 22.5$, as described by Matthews et al. [35].

All the experimental procedures followed during this investigation conformed to the Guide for the Care and Use of Laboratory Animals published by the US National Institutes of Health (NIH publication no. 8523, revised 1996) and to the guidelines established by the Animal Welfare Committee of La Plata School of Medicine. 


\section{PVAT measurements}

After sacrifice, thoracic aortas were quickly removed and placed in Petri dishes with chilled PBS. The adhered PVAT was dissected under a stereoscopic zoom microscope (Model SMZ645/660, Nikon Instruments Inc., Melvilla, NY, USA). Aliquots of fat tissue weighing 60 to $80 \mathrm{mg}$ were homogenized in a buffer solution containing $50 \mathrm{mM}$ Tris- $\mathrm{HCl}$ ( $\mathrm{pH} 7.4$ ), 1.15\% KCl, $1 \mathrm{mM}$ N-ethylmaleimide and $0.1 \% \mathrm{BHT}(\mathrm{v} / \mathrm{v})$ with a glass-teflon microhomogeneizer. The homogenates were centrifuged at $4^{\circ} \mathrm{C}(600 \times \mathrm{g})$ for $20 \mathrm{~min}$ and the resulting supernatants were assayed immediately or stored at $-70^{\circ} \mathrm{C}$ under argon atmosphere. The extent of lipid peroxidation was determined by measuring thiobarbituric acid reactive species (TBARS) by the method of Yagi [36] and expressed as nmol TBARS/mg wet tissue. Teraetoxypropane (Sigma) was used as standard for calibration.

Glutathione and enzymatic antioxidant activity were also determined in PVAT. Total glutathione (GSSG + GSH) was measured following the recycling enzymatic assay described by Brigelius et al. [37]. Superoxide dismutase activities (SOD) were assayed as described by Flohé and Ötting [38]. Glutathione peroxidase (GSHPx) and glutathione reductase (GSHRd) were determined according to Habig et al. [39] and Carlberg and Mannervik [40], respectively.

Nitric oxide (NO) content in the homogenates was estimated as the sum of nitrates plus nitrites (NOx), which results as the spontaneous and stable end-point degradation of NO. NOx level was measured with the spectrophotometric method described by Miranda et al. [41] using sodium nitrite as standard.

\section{Lipid composition analysis}

Appropriate aliquots of tissue homogenates were processed by c-GLC fatty acyl composition analysis. Briefly, total lipids were extracted by the method of Folch et al. [42]. c-GLC of fatty acid methyl esters (FAME) was performed as previously reported [43], except that in this case we used a capillary column (Supelco, Avondale, PA, USA) mounted on a Hewlett Packard HP 6890 Series GC System Plus (Avondale, PA) equipped with a terminal computer integrator system. FAME were identified by comparison of their relative retention times with authentic standards, and mass distribution was calculated electronically by quantification of the peak areas.

\section{Vascular reactivity studies}

The aortas were cut into 3-4 mm wide rings and gently suspended between two stainless steel wires in a waterjacketed organ bath containing Krebs-Ringer bicarbonate (KRB) solution with the following composition (in $\mathrm{mM}$ ): $130 \mathrm{NaCl}, 4.7 \mathrm{KCl}, 1.17 \mathrm{Na}_{2} \mathrm{HPO}_{4}, 1.16 \mathrm{MgSO}_{4}$, 24.0 $\mathrm{NaHCO}_{3}, 2.5 \mathrm{CaCl}_{2}$ and 6 glucose. The solution was continuously bubbled with a mixture of $5 \% \mathrm{CO}_{2}$ and $95 \% \mathrm{O}_{2}, \mathrm{pH} 7.4$, and kept at $37^{\circ} \mathrm{C}$. The lower wire was fixed to a vertical plastic rod immersed in the organ bath, while the upper one was rigidly attached to a force transducer (Letica TRI-201). Initially, arterial rings were stretched until attaining a force of $\approx 2 \mathrm{~g}$; thereafter, the rings were allowed to stabilize for $60 \mathrm{~min}$ and washed with fresh KRB every $20 \mathrm{~min}$. The signals from the force transducers were amplified and driven into an analog-digital board (DT16EZ, Data Translation, Inc., Marlboro, MA, USA) mounted in a desktop computer. On-line recordings and files for later processing were obtained with the appropriate software (Labtech Notebook Pro, Laboratory Technology Corp., Wilmington, MA, USA).

In some experiments, a high- $\mathrm{K}^{+} \mathrm{KRB}$ solution with the following composition was used (in $\mathrm{mM}$ ): $54.7 \mathrm{NaCl}, 80$ $\mathrm{KCl}, 1.17 \mathrm{Na}_{2} \mathrm{HPO}_{4}, 1.16 \mathrm{MgSO}_{4}, 24.0 \mathrm{NaCO} 3 \mathrm{H}, 2.5$ $\mathrm{CaCl}_{2}$ and 6.0 glucose.

To evaluate the potential modulatory role of adipose tissue, whereas some rings were dissected to remove the adherent PVAT, in others PVAT was left intact. In rings with an intact PVAT, a special protocol was developed to study the possible FRD-induced modifications on the relaxant effects of this tissue. For this purpose, a contraction was induced by $5 \mu \mathrm{M} 5-\mathrm{HT}$, which acts through the activation of membrane receptors of vascular smooth muscle. Thereafter, the rings were carefully dismounted from the chambers and PVAT was carefully removed with micro scissors under a stereoscopic zoom microscope. Afterwards, the rings were remounted in the chambers as described before (including the 1-h stabilization), and the 5-HT challenge protocol was repeated. In order to minimize differences among vascular rings, the results of this second exposure to $5-\mathrm{HT}$ were presented as paired to the first one, i.e., the change in the maximal force of the second contraction was expressed as a percentage of the first one. To test the effect of a different vessel contraction stimulatory pathway, we used a similar protocol (challenge of the intact ring followed by the same stimulus applied to the same ring after PVAT removal), but muscle contraction was triggered by high $\mathrm{K}^{+}$-induced depolarization.

In order to study whether vascular smooth muscle was affected by the FRD, appropriate controls were performed removing PVAT from CD and FRD rings after isolation of the aorta; the denuded rings were then subjected to the same two sequential steps of the protocol described above, including the demounting and remounting step between the two contractions. Although initially studies were performed using either intact or fatdeprived aorta rings, we later adopted the above mentioned procedure to obtain most consistent and least dispersed data. 


\section{Statistical analyses}

Results are expressed as means \pm SEM. One-way ANOVA followed by Bonferroni's test and Student's t-test were used for establishing statistically significant differences between groups. In all instances of statistical analysis, $\mathrm{P}<0.05$ was considered significant.

\section{Results}

Food intake, body weight and blood parameters

A comparable caloric intake was recorded in both experimental groups. CD and FRD rats consumed an average of 19.2 and $13.3 \mathrm{~g} / \mathrm{animal} /$ day; FRD animals also consumed $5.26 \mathrm{~g}$ fructose (calculated from the amount of fructose solution drinked daily). Accordingly, the food composition for CD vs. FRD rats was $45 \%$ carbohydrates, $43 \%$ proteins and $12 \%$ lipids $v$ s. $60 \%$ carbohydrates, $31 \%$ proteins and $9 \%$ lipids. Consequently, there was a small but not significant difference in caloric intake between $\mathrm{CD}$ and FRD rats $(55.65 \pm 4.54$ vs. 50.79 $\pm 3.43 \mathrm{kcal} /$ day, respectively), No differences were detected in initial and final body weight between the experimental groups.

There were no significant differences in fasting plasma glucose between groups (FRD vs. CD, $6.28 \pm 0.15$ vs. $6.05 \pm 0.15 \mathrm{mmol} / \mathrm{L}$ ). FRD rats, however, had significantly higher plasma triglyceride, fructosamine and insulin levels $(1.61 \pm 0.14$ vs. $1.13 \pm 0.08 \mathrm{mmol} / \mathrm{L}, \mathrm{P}<0.02$; $162.6 \pm 3.3$ vs. $146.2 \pm 5.6 \mu \mathrm{mol} / \mathrm{L}, \mathrm{P}<0.03 ; 1.12 \pm 0.04$ vs. $0.86 \pm 0.10, \mathrm{P}<0.05)$ as well as HOMA insulin resistance index $(7.66 \pm 0.31$ vs. $5.16 \pm 0.21, \mathrm{P}<0.001$, respectively) than $C D$ rats. These results validate the presence of an early fructose-induced metabolic disturbance and glucoxidative state in FRD rats, as described previously $[12,13,15]$.

\section{PVAT: FA composition, antioxidant defense system, TBARS and NOx}

The FA composition of total lipids extracted from PVAT of both experimental groups is shown in Table 1. FRD administration for 3 weeks increased the proportion of saturated myristic (14:0), palmitic (16:0) and stearic (18:0) acids by $37 \%, 17 \%$ and $24 \%$, respectively. Conversely, the stearic acid derivative oleic acid (18:1) showed a significant $22 \%$ decrease. The polyunsaturated fatty acids (PUFAs) of the n- 6 family showed an uneven behavior in FRD rats: the percentages of eicosatrienoic $(20: 3 n-6)$ and arachidonic (20:4n-6) FAs decreased significantly (66\% and $33 \%$, respectively), while the linoleic $(18: 2 n-6)$ and alpha and gamma-linolenic (18:3n-3) acid proportions remained unchanged. Thus, the total amount of PUFAs decreased significantly in FRD rats. Accordingly, the ratios of total saturated to monounsaturated FAs and total saturated FAs to PUFAs were higher in this experimental group.
Table 1 Fatty acid composition (mol \%) of total lipids of PVAT from CD and FRD rats

\begin{tabular}{lcc}
\hline FA & CD & FRD \\
\hline $\mathbf{1 4 : 0}$ (myristic acid) & $1.9 \pm 0.13$ & $2.6 \pm 0.10^{* * *}$ \\
$\mathbf{1 6 : 0}$ (palmitic acid) & $27.6 \pm 1.03$ & $32.3 \pm 0.70^{* *}$ \\
$\mathbf{1 6 : 1}$ (palmitoleic acid) & $1.0 \pm 0.09$ & $0.5 \pm 0.05^{* * *}$ \\
$\mathbf{1 8 : 0}$ (stearic acid) & $19.4 \pm 0.65$ & $24.1 \pm 0.65^{* * *}$ \\
$\mathbf{1 8 : 1}$ (oleic acid) & $12.8 \pm 0.35$ & $10.0 \pm 0.20^{* * *}$ \\
$\mathbf{1 8 : 2}$ n-6 (linoleic acid) & $15.4 \pm 0.33$ & $15.9 \pm 0.60$ \\
$\mathbf{1 8 : 3}$ n-3 $(\alpha$ and $\gamma$ linolenic acids) & $0.2 \pm 0.02$ & $0.2 \pm 0.01$ \\
$\mathbf{2 0 : 3}$ n-6 (eicosatrienoic acid) & $0.3 \pm 0.02$ & $0.1 \pm 0.02^{* * *}$ \\
$\mathbf{2 0 : 4}$ n-6 (arachidonic acid) & $21.6 \pm 1.53$ & $14.5 \pm 0.90^{* * *}$ \\
$\Sigma$ Sat $/ \boldsymbol{\Sigma}$ Mono & $3.62 \pm 0.08$ & $5.72 \pm 0.13^{* * *}$ \\
$\mathbf{\Sigma}$ PUFA & $37.5 \pm 0.74$ & $30.7 \pm 0.45^{* * *}$ \\
$\mathbf{\Sigma}$ Sat $/ \boldsymbol{\Sigma}$ PUFA & $1.31 \pm 0.04$ & $1.93 \pm 0.03 * * *$ \\
\hline
\end{tabular}

The values represent the means $\pm S E M ; n=11$ animals for each group. Asterisks indicate P values for differences between CD and FRD; ${ }^{* * *}<0.001$, ** $<0.01$.

CD: control; FRD: fructose-fed rats; Sat: saturated; Mono: monounsaturated; PUFA: polyunsaturated fatty acids.

FRD significantly modified those parameters related to the antioxidant defense system and the main biomarkers of oxidative damage (total GSH, TBARS and NOx). Total SOD and GSHPx activities as well as total glutathione content (GSH + GSSG) were significantly lower in PVAT homogenates of FRD rats. Conversely, TBARS content and total $\mathrm{NO}_{\mathrm{x}}$ and GSH-Rd activity were significantly higher in these rats (Table 2).

\section{Vascular reactivity studies}

Since it is known that PVAT attenuates the smooth muscle force development induced by 5 -HT $[24,25]$, we tested its effect (5 $\mu \mathrm{M}$ concentration) upon two paired contractions (intact and PVAT-deprived rings) of aorta rings obtained from $C D$ and FRD rats (see above). Removal of PVAT increased the developed force; as shown in Figure 1A, the second contraction (ring without PVAT) was bigger than the first one (intact ring). In the case of aortic rings from FRD animals, however, the increased force recorded after PVAT removal was significantly smaller than the one observed in rings obtained from CD animals (Figure 1A). This effect was no longer observed when the two contractions were performed in PVAT-deprived rings (Figure 1B). Additionally, the second contractions in these rings showed only a small and comparable increase in either CD or FRD rats (data not shown).

A similar experimental protocol was performed using high extracellular $\mathrm{K}^{+}$, that triggers smooth muscle cell contraction by depolarization and subsequent opening of voltage-operated $\mathrm{Ca}^{2+}$ channels. Results showed that PVAT does not affect the force development induced by depolarization; in fact, the percentage of increase of the 
Table 2 Oxidative stress markers measured in PVAT of CD and FRD rats

\begin{tabular}{lllllll}
\hline & $\begin{array}{l}\text { SOD } \\
(\mathbf{U} / \mathbf{m g})\end{array}$ & $\begin{array}{l}\text { GSH-Px } \\
(\mathbf{U} / \mathbf{m g})\end{array}$ & $\begin{array}{l}\text { GSH-Rd } \\
(\mathbf{U} / \mathbf{m g})\end{array}$ & $\begin{array}{l}\text { TBARS } \\
(\mathbf{n m o l} / \mathbf{m g})\end{array}$ & $\begin{array}{l}\mathbf{N O}_{\mathbf{x}} \\
(\mathbf{p m o l} / \mathbf{m g})\end{array}$ & $\begin{array}{l}\text { GSH + GSSG } \\
(\mathbf{p m o l} / \mathbf{m g})\end{array}$ \\
\hline $\mathrm{CD}^{\mathrm{a}}$ & $7.96 \pm 0.45$ & $12.14 \pm 0.94$ & $19.60 \pm 1.10$ & $0.27 \pm 0.01$ & $110.18 \pm 5.89$ & $88.40 \pm 4.42$ \\
$\mathrm{FRD}^{\mathrm{b}}$ & $4.98 \pm 0.13$ & $6.22 \pm 0.27$ & $26.85 \pm 1.15$ & $0.53 \pm 0.03$ & $215.38 \pm 5.03$ & $47.08 \pm 1.98$ \\
a vs. b, P & $<0.001$ & $<0.001$ & $<0.001$ & $<0.001$ & $<0.001$ & $<0.001$ \\
\hline
\end{tabular}

Values represent the means \pm SEM. $n=7$ animals for each group. CD: control; FRD: fructose-fed rats; SOD: superoxide dismutase; GSH-Px: glutathione peroxidase; GSH-Rd: glutathione reductase; TBARS: thiobarbituric acid reactive species; NOx: nitrates plus nitrites; GSH+GSSG: total content of glutathione in PVAT.

A

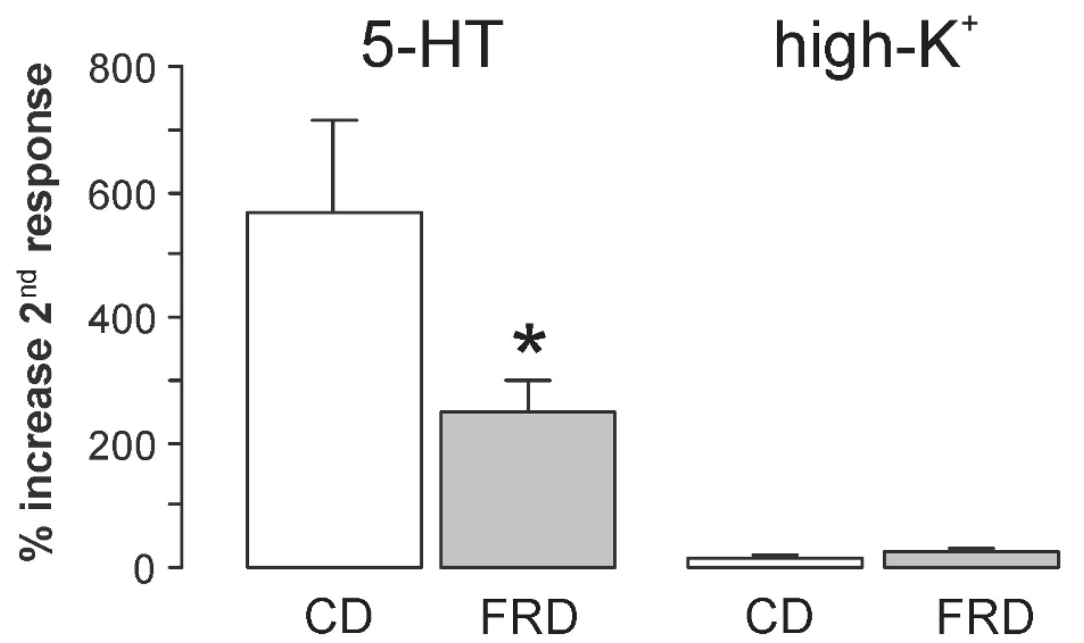

B

$5-\mathrm{HT}$

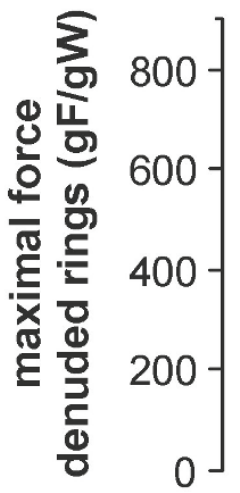

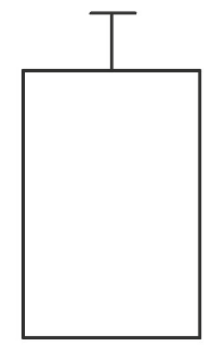

CD

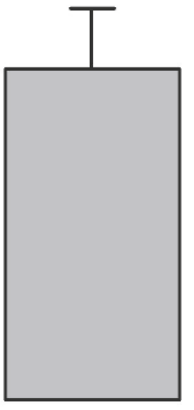

FRD

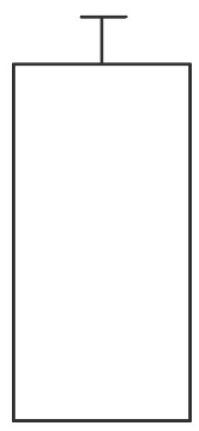

CD

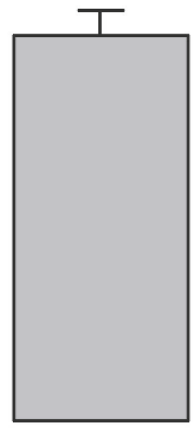

FRD

Figure 1 Vascular reactivity experiments with and without perivascular adipose tissue in CD and FRD animals. A. Increase in the maximal force of the second contraction (without PVAT) developed by aortic rings from CD and FRD animals stimulated with $5 \mu M$ 5-HT (CD, $n=17 ;$ FRD, $n=$ 15) or high- $K^{+} K R B(C D, n=20 ; F R D, n=17)$. Results are expressed as the increase of the contraction without PVAT compared to a previous contraction with PVAT whose maximal force is taken as $100 \%$. The asterisk indicates a statistically significant difference from the CD group. B. Maximal forces attained by denuded aortic rings (without PVAT) from CD and FRD animals stimulated with $5 \mu M$ 5-HT (CD, $n=8 ; F R D, n=7)$ or high-K ${ }^{+} K R B$ $(C D, n=8 ; F R D, n=9)$. 
second contraction (without PVAT) was small and of the same magnitude as that recorded in PVAT-deprived rings (Figure 1A). The lack of effect of PVAT on smooth muscle contractions induced by high extracellular $\mathrm{K}^{+}$was also observed in aortic rings obtained from FRD animals (Figure 1A). Furthermore, no differences were seen between $C D$ and FRD PVAT-deprived rings in the maximal force produced by depolarization with high $\mathrm{K}^{+}$(Figure 1B).

\section{Discussion}

\section{Blood parameters measured in the FRD- rats model}

As already reported, we have currently recorded a significant increase in plasma fructosamine level in rats fed a FRD for 3 weeks, indicating an increment in systemic protein glycosylation $[15,19]$. Since no differences were recorded in fasting glucose levels but FRD rats had IGT, we must assume that these rats present abnormally high postprandial glucose levels. FRD rats also had higher circulating insulin levels and HOMA score values, thus supporting the presence of an IR state. Hypertriglyceridemia - another IR-inducer [3,12,15,22] - was also present in these rats due to a combined effect of excess FA provision to the liver, decreased esterification in adipose tissue, and attenuation of the lowering effect of insulin on hepatic VLDL secretion. Such changes can be ascribed to a) the increased hepatic de novo lipogenesis observed during high carbohydrate feeding [44], b) the inhibition of lipoproteinlipase (LPL) activity reported in FRD rats [45], and c) the consequent decrease in VLDL and chylomicron hydrolysis.

\section{PVAT measurements \\ Lipid composition analysis and PVAT redox state}

In line with the above mentioned changes, PVAT fatty acyl lipid composition showed significant changes in FRD rats, mainly an increase in saturated FAs and a decrease in mono- and polyunsaturated FAs, resulting in a rise of the saturated/MUFA and saturated/PUFA ratios. We have previously reported similar changes in the abdominal adipose tissue of these rats, with increases in the saturated to unsaturated FAs ratios associated with decreases in the tissue's antioxidant defenses [12,13].

The PVAT redox state was also modified by the fructose overload, as shown by a) a decreased activity of key antioxidant enzymes such as SOD and GSH-Px, which account for the excessive production of superoxide anion and organic peroxides, respectively, b) a reduction in glutathione content, the major antioxidant of watersoluble cellular components, c) an increased GSH-Rd activity that likely reflects a compensatory mechanism to return oxidized glutathione to its reduced state, and d) a higher NO production, which may reflect the activation of the inducible isoform of NO synthase in response to the augmented oxidative stress. Altogether, these alterations decreased the cell capacity to cope with oxidative stress and are responsible for the recorded increase in biomarkers of oxidative damage, mainly lipid peroxidation products, estimated through the TBARS concentration in PVAT. As mentioned before, excessive chain breaking produced by reactive species is reflected in the altered saturated/unsaturated FAs ratio present in PVAT triglycerides. These changes resemble those reported in abdominal adipose tissue $[12,13,15]$, thus suggesting that they are the consequence of a general rather than a single local gluco-oxidative stress and can partly explain the association between adipose tissue and vascular dysfunction.

The presence of increased oxidative stress in different tissues of IR and diabetic animals has also been reported, such as a NO synthase dysfunction in Goto-Kakizaki rats, which could be attenuated by exercise [46], and increased ROS production in aortas of streptozotcin-diabetic mice, that was reverted by aminoguanidine administration [47].

\section{Vascular reactivity}

It has been reported that IR states and type 2 diabetes are associated to the development of vascular complications, mostly related to hyperglycemia, dyslipidemia, protein glycation and enhanced oxidative stress [48]. All these alterations are present in FRD rats, and animals fed with such diet for 8 weeks presented endothelial dysfunction related to reduced NO synthesis and increased oxidative stress [49].

In our study, we tested whether the significant FRDinduced changes on PVAT lipid composition and redox status affected vessel contractility. For that purpose, we used both intact and PVAT-deprived aorta rings and two different stimuli: a) 5-HT, because it induces a PVAT-dependent relaxant response [24], and b) depolarization by high extracellular $\mathrm{K}^{+}$, because it does not provoke relaxation in a PVAT-dependent fashion. Results showed that removal of PVAT increased the force developed by aortic rings in response to 5 - HT; however, such increase was significantly smaller in rings from FRD rats. This effect was no longer observed when the two contractions were performed in PVAT-deprived rings. On the other hand, no differences were recorded in rings from $C D$ and FRD rats in the contractile response to high extracellular $\mathrm{K}^{+}$, neither using intact nor PVAT-deprived rings. The latter effect was not unexpected, since factors released by PVAT would produce vascular smooth muscle relaxation through the hyperpolarization achieved by the opening of $\mathrm{K}^{+}$channels $[24,26,28]$, and $\mathrm{K}^{+}$channel activation does not hyperpolarize the cell when the extracellular $\mathrm{K}^{+}$concentration is high. Interestingly, there would be regional differences in the type of $\mathrm{K}^{+}$channels activated by PVAT 
relaxing factors: while in some vessels there are highconductance $\mathrm{Ca}^{2+}$-activated $\mathrm{K}^{+}$channels $\left(\mathrm{BK}_{\mathrm{Ca}}\right)$ [26], in others ATP-sensitive $\mathrm{K}^{+}$channels (K АтP) [24] or delayed-rectifier $\mathrm{K}^{+}$channels $\left(\mathrm{K}_{\mathrm{V}}\right)$ [28] are the target. We cannot rule out the possibility that agonists produced by the PVAT in FRD rats modified the vascular smooth muscle cells-IP3 receptor properties, as it occurred in rat models of type 1 diabetes [50].

As already mentioned, there were no differences in the contractile forces developed by 5 -HT or by high extracellular $\mathrm{K}^{+}$between $\mathrm{CD}$ and FRD rings without PVAT (Figure 1B). Consequently, the current results suggest that in FRD rats, at least in the period studied, the paracrine PVAT function rather than the smooth muscle function was affected. Comparable results regarding aortic rings without PVAT were reported by Verma et al. [51]: these authors found that administration of a diet supplemented with a fructose concentration higher than ours (66\% fructose) for 3 weeks did not affect vascular reactivity to noradrenaline.

The effect of PVAT upon vascular function could be ascribed to many molecules produced by this tissue. ROS, namely superoxide anion [30] and $\mathrm{H}_{2} \mathrm{O}_{2}$ [31] are two of the vasoactive substances released by PVAT. Thus, the change in the redox state (SOD and others) produced by the FRD will surely affect their concentrations. However, since superoxide anion promotes vessel contraction while $\mathrm{H}_{2} \mathrm{O}_{2}$ induces its relaxation, the final outcome will depend on their relative PVAT production/release balance. Further experiments are required to define whether the changes observed in the vascular response to $5-\mathrm{HT}$ are the consequence of the increased ROS production/action or just casually associated. In this regard, it would also be interesting to study whether FRD administration for a longer period accentuates the currently described PVAT alterations.

Despite the significant association between glucooxidative stress markers and relaxation changes recorded, some other factors released by PVAT, such as leptin [52], could also play a role as a signal in our model. In this regard, we have already reported that FRD-fed rats have high serum leptin levels and that their abdominal adipose tissue has a higher expression of its gene and releases larger amounts of leptin [13]. Considering that all the changes recorded in the parameters measured in PVAT are highly similar to those reported in abdominal adipose tissue, we could therefore assume that leptin's behaviour would follow the same pattern. Altogether, these results support the concept of the important role of the crosstalk between PVAT fat and vascular function $[53,54]$.

Even when we found a great coincidence among gluco-oxidative stress markers, changes in PVAT composition and those measured in vascular properties, other factors such as hypertension - present in the FRD model [8] - could also participate in the underlying mechanism responsible for the latter. Anyhow, and as part of the complex net of interactions present in this animal model, the increased formation of ROS also contributes to fructose-induced hypertension.

\section{Final remarks and conclusions}

The current results evidence that an increased intake of fructose induces multiple metabolic and endocrine systemic alterations which are concomitant with significant changes in PVAT fatty acyl composition and oxidative stress biomarkers. These changes were similar to those measured in abdominal adipose tissue in this rat model. While at this stage (3 weeks of treatment) the vascular smooth muscle response was still unaffected, alterations in the vascular relaxant properties dependent on the PVAT were already evident. These results should contribute to elucidate, at least partly, the strong association between adipose tissue and vascular dysfunction. They also suggest that at early stages of this rat model that resemble the human MS, alterations in the paracrine function of PVAT precede those of vascular smooth muscle. Finally, the FRD rat model represents a valuable experimental tool to study the effect of agents potentially able to prevent or attenuate the vascular pathology associated with the MS and type 2 diabetes. Further, high fructose diets certainly promote multiple undesirable metabolic and vascular disorders.

\section{Acknowledgements}

This work was partially supported with funds provided by the National Research Council of Argentina (CONICET). AR, CAM and JJG are members of the Research Career of CONICET. The authors thank Adriana Di Maggio for careful manuscript edition.

\section{Author details}

${ }^{1}$ GINFIV - Grupo de Investigación en Fisiología Vascular, Grupo Vinculado a CENEXA (UNLP - CONICET LA PLATA), Facultad de Ciencias Exactas, Universidad Nacional de La Plata, La Plata, Argentina. ${ }^{2}$ CENEXA - Centro de Endocrinología Experimental y Aplicada, UNLP-CONICET LA PLATA, Centro Colaborador OPS/OMS), Facultad de Ciencias Médicas, Universidad Nacional de La Plata. La Plata, Argentina. ${ }^{3}$ INIBIOLP - Instituto de Investigaciones Bioquímicas de La Plata, UNLP-CONICET LA PLATA, Cátedra de Bioquímica y Biología Molecular, Facultad de Ciencias Médicas, Universidad Nacional de La Plata, La Plata, Argentina.

Authors' contributions

$A R$ and JJG conceived and designed the study, performed the statistical analyses and drafted the manuscript. AR, ARRP and LR carried out the vascular reactivity experiments. CAM performed the enzymatic and lipid peroxidation assays. ORR and MEG carried out fructosamine, lipid, triglyceride and lipid peroxidation determinations. All authors read and approved the final manuscript.

\section{Competing interests}

The authors declare that they have no competing interests.

Received: 2 August 2010 Accepted: 21 October 2010 Published: 21 October 2010 


\section{References}

1. Grundy SM, Brewer HB, Cleeman Jl, Smith SC Jr, Lenfant C, American Heart Association; National Heart, Lung, and Blood Institute: Definition of metabolic syndrome: Report of the National Heart, Lung and Blood Institute/American Heart Association conference on scientific issues related to definition. Circulation 2004, 109:433-438

2. Bray GA, Nielsen SJ, Popkin BM: Consumption of high-fructose corn syrup in beverages may play a role in the epidemic of obesity. Am J Clin Nutr 2004, 79:537-543.

3. Girard A, Madani S, Boukortt F, Cherkaoui-Malki M, Belleville J, Prost J: Fructose-enriched diet modifies antioxidant status and lipid metabolism in spontaneously hypertensive rats. Nutrition 2006, 22:758-766.

4. Dai $\mathrm{S}$, Todd ME, Lee S, McNeill JH: Fructose loading induces cardiovascular and metabolic changes in nondiabetic and diabetic rats. Can J Physiol Pharmacol 1994, 72:771-781.

5. Gutman R, Basilico MZ, Bernal C, Chicco A, Lombardo YB: Long-term administration of a sucrose-rich diet to normal rats: relationship between metabolic and hormonal profiles and morphological changes in the endocrine pancreas. Metabolism 1987, 45:1527-1532.

6. Catena C, Giacchetti G, Novello M, Colussi G, Cavarape A, Sechi LA: Cellular mechanisms of insulin resistance in rats with fructose-induced hypertension. Am J Hypertens 2003, 16:973-978.

7. Tobey TA, Mondon CE, Zavaroni I, Reaven GM: Mechanism of insulin resistance in fructose-fed rats. Metabolism 1982, 31:608-612.

8. Tran LT, Yuen VG, McNeill JH: The fructose-fed rat: a review on the mechanisms of fructose-induced insulin resistance and hypertension. Mol Cell Biochem 2009, 332:145-159.

9. Bourgoin F, Bachelard $H$, Badeau M, Mélançon S, Pitre M, Larivière R, Nadeau A: Endothelial and vascular dysfunctions and insulin resistance in rats fed a high-fat, high-sucrose diet. Am J Physiol Heart Circ Physiol 2008, 295:H1044-H1055.

10. Romanko OP, Ali MI, Mintz JD, Stepp DW: Insulin resistance impairs endothelial function but not adrenergic reactivity or vascular structure in fructose-fed rats. Microcirculation 2009, 16:414-423.

11. Katakam PV, Ujhelyi MR, Hoenig ME, Miller AW: Endothelial dysfunction precedes hypertension in diet-induced insulin resistance. Am J Physiol 1998, 275(3 Pt 2):R788-792.

12. Rebolledo OR, Marra CA, Raschia A, Rodriguez S, Gagliardino JJ: Abdominal adipose tissue: early metabolic dysfunction associated to insulin resistance and oxidative stress induced by an unbalanced diet. Horm Metab Res 2008, 40:794-800.

13. Alzamendi A, Giovambattista A, Raschia A, Madrid V, Gaillard RC, Rebolledo O, Gagliardino JJ, Spinedi E: Fructose-rich diet-induced abdominal adipose tissue endocrine dysfunction in normal male rats. Endocrine 2009, 35:227-232.

14. Maiztegui B, Borelli MI, Raschia MA, Del Zotto H, Gagliardino JJ: Islet adaptive changes to fructose-induced insulin resistance: $\beta$-cell mass, glucokinase, glucose metabolism and insulin secretion. J Endocrinol 2009, 200:139-49.

15. García ME, Marra CA, Rebolledo OR: Glycoxidative stress-induced damage on lípid profile in a fructose-enriched diet model of insulin resistance in rats. Arch Physiol Biochem 2010, 116:42-49.

16. Francini F, Castro MC, Schinella G, García ME, Maiztegui B, Raschia MA, Gagliardino JJ, Massa ML: Changes induced by a fructose-rich diet on hepatic metabolism and the antioxidant system. Life Sci 2010, 86:965-971.

17. Wolff SP, Dean RT: Glucose autoxidation and protein modification. The potential role of "autoxidative glycosylation" in diabetes. Biochem J 1987, 245:243-250.

18. Lyons TJ, Jenkins AJ: Glycation, oxidation, and lipoxidation in the development of the complications of diabetes: a carbonyl stress hypothesis. Diabetes Rev 1997, 5:365-391.

19. Brownlee M: Negative consequences of glycation. Metabolism 2000, 49:9-13.

20. Faure P, Rossini E, Lafond JL, Richard MJ, Favier A, Halimi S: Vitamin E improves the free radical defense system potential and insulin sensitivity of rats fed high fructose diets. J Nutr 1997, 127:103-107.

21. Busserolles J, Zimowska W, Rock E, Rayssiguier Y, Mazur A: Rats fed a high sucrose diet have altered heart antioxidant enzyme activity and gene expression. Life Sci 2002, 71:1303-1312.
22. Thirunavukkarasu V, Anitha Nandhini AT, Anuradha CV: Cardiac lipids and antioxidant status in high fructose rats and the effect of alpha-lipoic acid. Nutr Metab Cardiovasc Dis 2004, 14:351-357.

23. Delbosc S, Paizanis E, Magous R, Araiz C, Dimo T, Cristol JP, Cros G, Azay J: Involvement of oxidative stress and $\mathrm{NADPH}$ oxidase activation in the development of cardiovascular complications in a model of insulin resistance, the fructose-fed rat. Atherosclerosis 2005, 179:43-49.

24. Löhn M, Dubrovska G, Lauterbach B, Luft FC, Gollasch M, Sharma AM: Periadventitial fat releases a vascular relaxing factor. FASEB J 2002, 16:1057-1063

25. Dubrovska G, Verlohren S, Luft FC, Gollasch M: Mechanisms of ADRF release from rat aortic adventitial adipose tissue. Am J Physiol Heart Circ Physiol 2004, 286:H1107-H1113.

26. Gao YJ, Zeng ZH, Teoh K, Sharma AM, Abouzahr L, Cybulsky I, Lamy A Semelhago L, Lee RM: Perivascular adipose tissue modulates vascular function in the human internal thoracic artery. J Thorac Cardiovasc Surg 2005, 130:1130-1136.

27. Fésüs G, Dubrovska G, Gorzelniak K, Kluge R, Huang Y, Luft FC, Gollasch M: Adiponectin is a novel humoral vasodilator. Cardiovasc Res 2007 75:719-727.

28. Verlohren S, Dubrovska G, Tsang SY, Essin K, Luft FC, Huang Y, Gollasch M: Visceral periadventitial adipose tissue regulates arterial tone of mesenteric arteries. Hypertension 2004, 44:271-276.

29. Ouwens DM, Sell H, Greulich S, Eckel J: The role of epicardial and perivascular adipose tissue in the pathophysiology of cardiovascular disease. J Cell Mol Med 2010

30. Gao YJ, Takemori K, Su LY, An WS, Lu C, Sharma AM, Lee RM: Perivascular adipose tissue promotes vasoconstriction: the role of superoxide anion. Cardiovasc Res 2006, 71:363-373.

31. Gao YJ, Lu C, Su LY, Sharma AM, Lee RM: Modulation of vascular function by perivascular adipose tissue: the role of endothelium and hydrogen peroxide. $\mathrm{Br} J$ Pharmacol 2007, 151:323-331.

32. Rittig K, Staib K, Machann J, Böttcher M, Peter A, Schick F, Claussen C, Stefan N, Fritsche A, Häring HU, Balletshofer B: Perivascular fatty tissue at the brachial artery is linked to insulin resistance but not to local endothelial dysfunction. Diabetologia 2008, 51:2093-2099.

33. Marra CA, de Alaniz MJT: Acyl-CoA synthetase activity in liver microsomess from calcium-deficient rats. Lipids 1999, 34:343-354.

34. Reeves PG, Nielsen FH, Fahley GC Jr: AIN-93 Purified diets for laboratory rodents: final report of the American Institute of Nutrition ad hoc writing committee on the reformulation of the AIN-76A rodent diet. $J$ Nutr 1993, 123:1939-1951.

35. Matthews DR, Hosker JP, Rudensky AS, Naylor BA, Treacher DF, Turner RC Homeostasis model assessement: insulin resistance and beta cell function for fasting plasma glucose and insulin concentrations in man Diabetologia 1985, 28:412-419.

36. Yagi K: A simple fluorimetric assay for lipoperoxide in blood plasma. Biochem Med 1976, 15:212-216.

37. Brigelius R, Muckel C, Akerboom TP, Sies H: Identification and quantitation of glutathione in hepatic protein mixed disulfides and its relationship to glutathione disulfide. Biochem Pharmacol 1983, 32:2529-2534.

38. Flohé L, Ötting F: Superoxide dismutase assays. Methods Enzymol 1984 105:93-104.

39. Habig WH, Pabst MJ, Jakoby WB: Glutathione-S-transferases. The first enzymatic step in mercapturic acid formation. J Biol Chem 1974 249:7130-7139.

40. Carlberg I, Mannervik B: Glutathione reductase. Methods Enzymol 1985, 113:484-490.

41. Miranda KM, Espey MG, Wink DA: A rapid, simple spectrophotometric method for simultaneous detection of nitrate and nitrite. Nitric Oxide 2001, 5:62-71.

42. Folch J, Lees M, Sloane Stanley GH: A simple method for the isolation and purification of total lipides from animal tissues. J Biol Chem 1957, 226:497-509.

43. Marra CA, de Alaniz MJ: Incorporation and metabolic conversion of saturated and unsaturated fatty acids in SK-Hep1 human hepatoma cells in culture. Mol Cell Biochem 1992, 117:107-118.

44. Mayes PA: Intermediary metabolism of fructose. Am J Clin Nutr 1993 58:754S-765S 
45. Picard F, Boivin A, Lalonde J, Deshaies Y: Resistance of adipose tissue lipoproteinlipase to insulin action in rats fed an obesity-promoting diet. Am J Physiol Endocr Metab 2002, 282:E412-E418.

46. Grijalva J, Hicks S, Zhao X, Medikayala S, Kaminski PM, Wolin MS, Edwards JG: Exercise training enhanced myocardial endothelial nitric oxide synthase (eNOS) function in diabetic Goto-Kakizaki (GK) rats. Cardiovasc Diabetol 2008, 7:34.

47. Oak JH, Youn JY, Cai H: Aminoguanidine inhibits aortic hydrogen peroxide production, VSMC NOX activity and hypercontractility in diabetic mice. Cardiovasc Diabetol 2009, 8:65.

48. Orasanu G, Plutzky J: The pathologic continuum of diabetic vascular disease. J Am Coll Cardiol 2009, 53:S35-42.

49. Shinozaki K, Nishio Y, Okamura T, Yoshida Y, Maegawa H, Kojima H, Masada M, Toda N, Kikkawa R, Kashiwagi A: Oral administration of tetrahydrobiopterin prevents endothelial dysfunction and vascular oxidative stress in the aortas of insulin-resistant rats. Circ Res 2000, 87:566-573.

50. Searls YM, Loganathan R, Smirnova IV, Stehno-Bittel L: Intracellular Ca2+ regulating proteins in vascular smooth muscle cells are altered with type 1 diabetes due to the direct effects of hyperglycemia. Cardiovasc Diabetol 2010, 9:8.

51. Verma S, Bhanot S, Yao L, McNeill JH: Defective endothelium-dependent relaxation in fructose-hypertensive rats. Am J Hypertens 1996, 9(4 Pt 1):370-376.

52. Knudson JD, Payne GA, Borbouse L, Tune JD: Leptin and mechanisms of endothelial dysfunction and cardiovascular disease. Curr Hypertens Rep 2008, 10:434-439.

53. Sommer G, Kralisch S, Stangl V, Vietzke A, Köhler U, Stepan H, Faber R, Schubert A, Lössner U, Bluher M, Stumvoll M, Fasshauer M: Secretory products from human adipocytes stimulate proinflammatory cytokine secretion from human endothelial cells. J Cell Biochem 2009, 106:729-737.

54. Guzik TJ, Marvar PJ, Czesnikiewicz-Guzik M, Korbut R: Perivascular adipose tissue as a messenger of the brain-vessel axis: role in vascular inflammation and dysfunction. J Physiol Pharmacol 2007, 58:591-610.

doi:10.1186/1475-2840-9-65

Cite this article as: Rebolledo et al.: Early alterations in vascular contractility associated to changes in fatty acid composition and oxidative stress markers in perivascular adipose tissue. Cardiovascular Diabetology 2010 9:65.

\section{Submit your next manuscript to BioMed Central and take full advantage of:}

- Convenient online submission

- Thorough peer review

- No space constraints or color figure charges

- Immediate publication on acceptance

- Inclusion in PubMed, CAS, Scopus and Google Scholar

- Research which is freely available for redistribution

Submit your manuscript at www.biomedcentral.com/submit
Biomed Central 